\title{
Transanal endoscopic microsurgical excision of rectal tumors: Indications and results
}

\author{
Demartines, Nicolas ; von Flüe, Marcus O ; Harder, Felix H
}

\begin{abstract}
Transanal endoscopic microsurgery (TEM) allows local excision of rectal tumors located 4 to $18 \mathrm{~cm}$ above the anal verge. The technique is not yet generally established because of the necessary special instrumentation and tools, the unusual technical aspects of the approach, and the stringent patient selection criteria. The aim of this prospective, descriptive study was to analyze the currently accepted indications for TEM and to evaluate the use of this procedure for treating rectal cancer. Over a 4year period 50 patients aged 31 to 86 years (mean 64 years) underwent TEM for treatment of rectal tumors located $12 \mathrm{~cm}$ above the anal verge (range $4-18 \mathrm{~cm}$ ). The local complication rate was $4 \%$. Altogether, $76 \%$ of lesions were benign, and $24 \%$ were T1 and T2 tumors. Of 12 cancer cases, 4 required reoperation by total mesorectal resection; the other 8 are currently under follow-up management. Over the follow-up period of 30.6 months (range 11-54 months) the recurrence rate of T1 tumors was $8.3 \%$. TEM is a minimally invasive surgical technique that may benefit a small, specific population of patients with rectal tumors. Compared with conventional transanal resection, TEM provides superior exposure of tumors higher up in the rectum (i.e., up to $18 \mathrm{~cm}$ from the anal verge). The greater precision of resection combined with low morbidity (10\%, relative to that of anterior resection) and short duration of hospitalization (5.5 days) make this technique a reliable and in some cases more effective surgical approach than laparotomy and low anterior resection
\end{abstract}

DOI: https://doi.org/10.1007/s00268-001-0043-2

Posted at the Zurich Open Repository and Archive, University of Zurich

ZORA URL: https://doi.org/10.5167/uzh-156327

Journal Article

Published Version

Originally published at:

Demartines, Nicolas; von Flüe, Marcus O; Harder, Felix H (2001). Transanal endoscopic microsurgical excision of rectal tumors: Indications and results. World Journal of Surgery, 25(7):870-875.

DOI: https://doi.org/10.1007/s00268-001-0043-2 


\title{
Transanal Endoscopic Microsurgical Excision of Rectal Tumors: Indications and Results
}

\author{
Nicolas Demartines, M.D., ${ }^{1,3}$ Marcus O. von Flüe, M.D., ${ }^{2}$ Felix H. Harder, M.D. ${ }^{1}$ \\ ${ }^{1}$ Department of Surgery, University Hospital of Basel, Spitalstrasse 21, CH-4031 Basel, Switzerland \\ ${ }^{2}$ Department of Surgery A, Kantonsspital of Lucerne, Lucerne, Switzerland \\ ${ }^{3}$ Department of Surgery, University Hospital of Zurich, Raemistrasse 100, CH-8091 Zurich, Switzerland
}

\begin{abstract}
Transanal endoscopic microsurgery (TEM) allows local excision of rectal tumors located 4 to $18 \mathrm{~cm}$ above the anal verge. The technique is not yet generally established because of the necessary special instrumentation and tools, the unusual technical aspects of the approach, and the stringent patient selection criteria. The aim of this prospective, descriptive study was to analyze the currently accepted indications for TEM and to evaluate the use of this procedure for treating rectal cancer. Over a 4-year period 50 patients aged 31 to 86 years (mean 64 years) underwent TEM for treatment of rectal tumors located $12 \mathrm{~cm}$ above the anal verge (range $4-18 \mathrm{~cm}$ ). The local complication rate was $4 \%$. Altogether, $76 \%$ of lesions were benign, and $24 \%$ were $\mathrm{T} 1$ and $\mathrm{T} 2$ tumors. of 12 cancer cases, 4 required reoperation by total mesorectal resection; the other 8 are currently under follow-up management. Over the follow-up period of 30.6 months (range 11-54 months) the recurrence rate of $\mathrm{T} 1$ tumors was $8.3 \%$. TEM is a minimally invasive surgical technique that may benefit a small, specific population of patients with rectal tumors. Compared with conventional transanal resection, TEM provides superior exposure of tumors higher up in the rectum (i.e., up to $18 \mathrm{~cm}$ from the anal verge). The greater precision of resection combined with low morbidity ( $10 \%$, relative to that of anterior resection) and short duration of hospitalization ( 5.5 days) make this technique a reliable and in some cases more effective surgical approach than laparotomy and low anterior resection.
\end{abstract}

The introduction of transanal endoscopic microsurgery (TEM) by Buess et al. in 1983 realized an interesting technical advance in localized surgical treatment of rectal tumors [1]. TEM is a minimally invasive technique that allows precise resection of tumors located 2 to $18 \mathrm{~cm}$ from the anal verge using an operative microscope. Thus laparotomy is no longer the only option for managing such cases. However, the number of patients treated by TEM by Buess et al. during the 15 years since its introduction totaled only 500 [2], so the worldwide experience is limited. Reasons may include the high cost of TEM equipment (up to $\$ 80,000$ ), a small candidate pool, the stringent criteria for patient selection and indications for the procedure [3], and a highly demanding surgical technique that requires specialized training [3].

To date, there are only 109 publications on TEM listed by Medline. Most of these published series report the experience of Buess and his current and former staff members, with only a few

Correspondence to: N. Demartines, M.D., e-mail: nicolas.demartines@ chi.usz.ch reports on the results obtained at other medical centers in Europe (Italy, United Kingdom), the United States, and Japan. Thus the reliability of this new method has been demonstrated primarily by its inventor, and it must now be evaluated by the broader surgical community, especially given the current controversy surrounding localized management of rectal cancer $[4,5]$. The present study reports the experience of a department of general surgery at a university hospital, with the goals of analyzing the currently accepted indications for TEM and evaluating the use of this procedure for treating rectal cancer.

\section{Patients, Materials, Methods}

Between January 1995 and September 1999, all patients with rectal tumors were examined in our interdisciplinary coloproctology consultation practice. Following clinical examination, a biopsy was obtained in all patients, and endorectal sonography was performed using a 360 -degree endoprobe with an inflatable balloon at a frequency of $7 \mathrm{MHz}$ to diagnose possible wall infiltration. This endosonographic technique has approximately $90 \%$ diagnostic accuracy [6]. Simultaneously, we tested the integrity of sphincter function and assessed patient continence using the Kirwan-Parks classification system [7]. Anal manometry was performed only in cases of prolonged postoperative incontinence.

Preoperative assessment to stage and grade the type and severity of tumor resulted in two patient groups: The largest group had benign rectal tumor, and the smallest group had proven rectal cancer. Benign tumor and low risk rectal cancer were considered for TEM resection. Low risk rectal cancer was defined as a well or moderately differentiated (G1, G2) T1 tumor without lymphangiosis carcinomatosa [8]. All other types of cancer were excluded. Indications for TEM were defined as: (1) a benign tumor of any type $>2 \mathrm{~cm}$ in diameter; (2) adenoma recurrence; (3) low risk rectal cancer; and (4) rectal stenosis after fistula or anastomosis.

Tumors located 2 to $18 \mathrm{~cm}$ from the anal verge were treated by TEM. Tumors 2 to $4 \mathrm{~cm}$ from the anal verge were considered inappropriate for TEM because this setting prohibited proper introduction of the $40 \mathrm{~mm}$ operating microscope. These patients 
underwent conventional transanal surgical treatment using the Lone Star Retractor (Lone Star Medical Product, Houston, TX. USA) and were excluded from the study.

\section{TEM Technique}

The bowel was prepared as for a formal laparotomy by lavage over 4 hours with 3 to 4 liters of polyethylene glycol solution. Antibiotic prophylaxis for gram-negative and anaerobic strains was given at the time of anesthetic induction. Following the technique described by Buess et al. [1.9], we used an operative rectoscope of $40 \mathrm{~mm}$ diameter and 120 or $200 \mathrm{~mm}$ length, with a sixfold magnified stereoscopic view. The tip of the rectoscope is beveled downward. The patient's position for surgery therefore depends on the anteroposterior and lateral orientation of the tumor.

To visualize the anatomic relation between tumor and healthy mucosa, $\mathrm{CO}_{2}$ is insufflated to enlarge the intrarectal space and facilitate precise resection. This requires use of a combination suction-insuffation endosurgical unit to ensure constant, high flow of gas and to evacuate the smoke due to coagulation. The operation itself was performed as described originally by Buess et al. $[1,9]$. The use of a multifunctional instrument (suction/irrigation, coagulation, cutting) (ERBE, Elektromedizin GmbH, Tübingen, Germany) eased and sped up the procedure.

To optimize access to the entire tumor, the rectoscope orientation must be changed frequently to compensate for the limited operating field and length of the surgical instruments. Finally, the resection specimen is affixed to a preparation plate to allow the pathologists a precise description of the resection margin in $5 \mathrm{~mm}$ of healthy tissue

Postoperatively, patients are allowed to sit and walk as soon as they are fully recovered from anesthesia. A liquid diet is maintained for 24 hours, and patients are discharged on postoperative day 2 or 3 . Initial clinical follow-up occurs at 6 weeks postoperatively and the final clinical examination, including endorectal sonography, at 3 months.

\section{Data Analysis}

Patient data were prospectively collected on a personal computer and managed using Microsoft Excel. Descriptive statistics were used, and results are expressed as the absolute value, percent, mean, and range.

\section{Results}

Over the 4-year period of study, 50 patients satisfied the indications for TEM and were included in the study. Of these, 19 were female and 31 male, with a median age of 65 years (range $31-86$ years). All underwent surgery for a tumor located a mean $12 \mathrm{~cm}$ from the anal verge (range $4-18 \mathrm{~cm}$ ). Rectal blood loss was the leading symptom in 31 cases $(66 \%)$. The tumor was found incidentally by routine examination in 5 cases (10\%). All other patients presented with loss of mucus or nonspecific pain during defecation.

Preoperative endorectal sonography correctly staged the tumor in 45 cases $(90 \%)$. "Overstaging" occurred in 3 cases $(6 \%)$ and "understaging" in 2 cases ( $4 \%$ ).

Of the 50 procedures, 31 were performed in the lateral position $(62 \%) .13$ in the "jackknife prone" position (26\%), and 6 in the
Table 1 . TEM resections.

\begin{tabular}{lcr}
\hline Diagnosis $(n=50)$ & No. & $\%$ \\
\hline Villous adenoma & 35 & 70 \\
Rectal cancer & 12 & 24 \\
Carcinoid tumor & 1 & 2 \\
Stenosis & 1 & 2 \\
Recurrence (adenoma) & 1 & 2
\end{tabular}

TEM: transanal endoscopic microsurgical excision.

"lithotomy" position (12\%). Forty-two cases were performed under general anesthesia $(84 \%)$ and 8 under regional anesthesia (16\%). The average operating time was 117 minutes (range $45-$ 240 minutes).

Full-thickness resection (mucosa and serosa until perirectal fat) was performed in 45 cases ( $90 \%$ ) and mucosectomy in 5 cases $(10 \%)$. We decided to convert one case intraoperatively to laparotomy to avoid any oncologic risk due to rectal wall infiltration. This case was not excluded from the TEM data analysis. There were two cases of inadvertent peritoneal entry $(2 / 50,4 \%)$ associated with resection of tumors located 16 and $18 \mathrm{~cm}$ from the anal verge, respectively. One case required laparotomy, and the other resolved following a conservative 4-week course of treatment with protective loop sigmoidostomy. In addition, there were five systemic complications $(5 / 50,10 \%)$ : four minor problems (e.g., urine infection) and one major problem (myocardial infarction). There was no mortality.

Postoperative pain was rare, and the median hospitalization was 5.5 days (range $2-20$ days). The patient who sustained a myocardial infarction remained hospitalized for 20 days owing to the development of pneumonia. Reoperation was required in 5 of 50 cases $(10 \%)$, involving laparotomy and total mesorectal resection [10] for four cases of cancer and anterior resection for one case of rectal wall perforation and peritoneal entry followed by abscess.

Assessment of sphincter function revealed one 85-year-old patient who was incontinent (grade III, liquids and solids) preoperatively and remained so postoperatively. Six patients (12\%) who were initially continent developed incontinence (grade II, liquids and gas) during the first 2 weeks after operation. Clinical follow-up at 3 months showed that all six patients had fully recovered. Manometric studies were not performed in these cases.

\section{Histology}

Lesions were benign in 38 cases (76\%) and malignant in 12 cases (24\%). The histologic diagnosis indicated 32 villous adenomas $(64 \%) .9 \mathrm{~T} 1(18 \%)$ and $3 \mathrm{~T} 2(6 \%)$ rectal tumors, 3 polyps $(6 \%)$, 1 carcinoid ( $2 \%), 1$ recurrent polyp ( $2 \%$ ), and 1 rectal stenosis after a high fistula (2\%). The results are summarized in Table 1 with the tumor grading and additional treatment in Table 2. A diagnosis of cancer was known in eight cases, suspected in two cases, and surprising in two other cases. Four cases of cancer (two $\mathrm{T} 2$ lesions and two $\mathrm{T} 1$ tumors) required reoperation by total mesorectal resection (Table 2 ).

The T1 tumors were resected by TEM with a safe margin of at least $5 \mathrm{~mm}$ and are under follow-up management. One 85-yearold patient with a $\mathrm{T} 2$ tumor refused additional treatment by laparotomy or radiotherapy and died of concurrent disease 6 months postoperatively. 
Table 2. Cancers resected by TEM $(n=12)$.

\begin{tabular}{lll}
\hline Stage & Grade & Treatment \\
\hline $9 \mathrm{pT} 1$ & $1 \mathrm{G} 1,6 \mathrm{G}_{2}$ & Follow-up $(n=7)$ \\
& $1 \mathrm{G} 2$ & Adjuwant therapy $(n=1)$ \\
$3 \mathrm{pT} 2$ & $1 \mathrm{G} 3$ & Totat mesorectal resection $(n=1)$ \\
& $3 \mathrm{G} 2$ & Total mesorectal resection $(n=2)$ \\
& & Follow-up (patient in poor condition) $(n=1)$ \\
\hline
\end{tabular}

Recurrence rate at 30 months was $8.3 \%$.

Over the follow-up period of 30.6 months (range 11-54 months) the recurrence rate of $\mathrm{Tl}$ tumor was $8.3 \% ; 14$ months after TEM resection we detected one case of local recurrence. This patient was consequently treated by laparotomy and total mesorectal resection and is now under follow-up management.

\section{Discussion}

As minimally invasive surgical technique, TEM may benefit a small, specific population of patients diagnosed with rectal tumors. It offers the promise of localized treatment of these tumors, with relatively few complications and rare mortality. However, experience with TEM has been limited primarily to those who developed the technique and only a few others, making it necessary to reexamine functional outcome based on current indications and criteria for patient selection for this procedure.

Our results with TEM indicate that this technique is reproducible after surgical training, and that there is a clear benefit for the patients with minimal complications, avoiding laparotomy with anterior rectum resection. Because they are based on currently published indications and criteria for patient selection, our findings suggest that these standards remain adequate for identifying appropriate surgical candidates for TEM. We are not associated with the developers of TEM, so our results provide an independent perspective on the value of the technique. However, our series is small and nonrandomized, making larger additional prospective and randomized studies essential to confirm the true value of TEM for treatment of early rectal cancer.

The TEM technique distinguishes itself from other endoscopic or laparoscopic procedures in various ways. (1) It uses a magnified binocular stereoscopic device. Compared with the view obtained with monocular instruments or video cameras, the view of the operating field obtained with TEM provides a depth of field of extremely good quality. (2) Surgical instruments are inserted and moved in parallel planes unlike laparoscopy, necessitating specialized training and skill to achieve full tumor exposure. (3) Costly equipment (about $\$ 80,000$ ) is required. The cost of TEM equipment, combined with the relatively low incidence of the pathologies for which this procedure is indicated, have limited worldwide experience with this technique to a few surgical teams.

One clear advantage of TEM is an uneventful postoperative course. The postoperative analgesic requirement is slight, generally limited to a few doses of paracetamol [11]. Moreover, the duration of hospitalization (5.7 days for TEM versus 14.5 days, $p<0.0001)[11]$ and the complication rate (21\% versus $35 \%)[11]$ are significantly lower than those reported for low anterior resection. Overall, the localized complication rate associated with transanal resection lies between $4.0 \%$ and $8.3 \%$ of cases $[2,12]$ and that for systemic complications between $14 \%$ and $21 \%$ (Table
Table 3. TEM complication rate: review of the relevant literature.

\begin{tabular}{lrll}
\hline Year & No. & Complications (\%) & Reference \\
\hline 1996 & 313 & 4.5 & 13 \\
1996 & 50 & 20.6 (systemic) & 11 \\
1996 & 100 & 4.0 & 14 \\
1996 & 153 & 20.0 (systemic) & 15 \\
1997 & 27 & 4.0 & 16 \\
1997 & 423 & 8.3 & 2 \\
1998 & 226 & 4.1 & 17 \\
1998 & 46 & 2.3 & 18 \\
1998 & 73 & 5.0 & 19 \\
1999 & 50 & 4.0 & Present study \\
\hline
\end{tabular}

3) $[11,15,20]$. The results in our patients are comparable (i.e., a hospital stay of 5.5 days and localized and systemic complication rates of $4 \%$ and $10 \%$, respectively, with no mortality). In fact, mortality is rare: Of 109 publications describing the worldwide experience of about 3000 TEM cases (Table 3), only one German study reported a fatality: a unique, lethal complication of retroperitoneal phlegmon after TEM resection of an adenoma located $7 \mathrm{~cm}$ from the anal verge in a 55 -year-old patient who died in septic shock after 28 days [21].

\section{Effect on Sphincter Function}

It is surprising that prolonged anal dilatation with $4 \mathrm{~cm}$ diameter (the operative rectoscope) induces few sphincter function problems. We observed only postoperative transitory grade II incontinence in $12 \%$ of our patients, with full postoperative recovery after 3 months (excluding one elderly patient with chronic incontinence that did not resolve with surgery). Because this duration of incontinence was comparable to that already reported [22-24], we did not conduct manometric studies. However, existing manometric analyses of the effects of anal dilatation indicated a decrease in sphincter tonus ranging from $25 \%$ to $37 \%$ of preoperative sphincter pressure, with complete recovery to clinical continence within 6 to 16 weeks postoperatively [22-24].

\section{Indications for TEM}

The ideal indications for TEM are all types of adenoma located 4 to $18 \mathrm{~cm}$ of the anal verge that cannot be treated by colonoscopy. Ideal tumor size ranges in diameter from $20 \mathrm{~mm}$ to three-fourths of the lumen circumference. A full-thickness resection is recommended to ensure an appropriate margin of safety. In addition, this procedure is technically easier to perform than mucosectomy and decreases the risk of missing a small rectal cancer that may be located inside the villous adenoma. Such "in situ" cancers have been reported in up to $31 \%$ of cases [25]. Because the rectal wall is sutured after full-thickness resection, removal of a large segment of the rectum is not a high risk procedure based on the low morbidity reported in the literature (Table 3) and in our own series.

Rectal Cancer. Treatment of rectal cancer by TEM is generally accepted for T1 low risk cancer [2]. The recurrence rate following this application lies between $4 \%$ and $8 \%[2,18,19,26]$ compared with a local recurrence rate of up to $30 \%$ for $\mathrm{T} 1$ high risk cancer [27]. Patient selection is therefore crucial to good local and oncologic results. 
Other Indications. The following indications are rather anecdotal but are mentioned for complete information. TEM may be a suitable method for resecting stenoses 5 to $15 \mathrm{~cm}$ from the dentate line (e.g., inflammatory stenosis after a high fistula, as in our experience, or colorectal anastomotic stenosis. as described in Japan [28]). Other indications, such as transanal rectopexy originally proposed by Buess, no longer appears in the literature and there are no subsequent reports [29], suggesting that this indication is not to be recommended.

Transcutaneous application of TEM to treat early gastric cancer was first described in 1997 [30]. However, no follow-up has been reported, making even a preliminary conclusion questionable.

\section{Patient Selection}

Careful patient selection is crucial to TEM outcome. Preoperative staging must be precise. Specifically, a specimen should be available for histology, and the tumor should be visualized with the rigid rectoscope to determine its distance from the dentate line and localize it precisely in the quadrant. Endorectal sonography should be performed to assess eventual wall infiltration. Such precise staging is reportedly possible with an accuracy of up to $90 \%[6,31]$. In the present study, preoperative staging was correct in $90 \%$ of cases ( $n=45$ patients), resulted in an overestimate of tumor severity in $6 \%(n=3)$ and an underestimate in $4 \%(n=2)$. Incorrect estimation is a known phenomenon that depends on the accuracy of endoluminal sonography, which is examiner-dependent (learning curve) and described in up to $10 \%$ of the cases $[6$, 31). Only one procedure had to be converted to laparotomy during the primary operation owing to underestimated lesion severity, and it occurred early in our experience with the technique.

\section{Limitations of TEM for Treatment of Cancer}

The primary factor limiting the effectiveness of local treatment of early rectal cancer is lymph node invasion. The lymph node metastasis rate of $\mathrm{T} 1$ rectal tumors is between $0 \%$ and $15.4 \%$, depending on tumor grading $[27,32,33]$. Age less than 45 years is recognized as a significant risk factor for such metastasis [33]. Our population and those in many other studies have a reported age range of 31 to 86 years (median 65 years), suggesting the potential presence of high risk.

Local excision appears to offer a significant advantage. The rate of recurrence for $\mathrm{T} 1$ tumors resected by TEM lies between $3.8 \%$ and $8.0 \%$ at 13 months follow-up $[18,19,26]$ compared with a recurtence rate of $23.0 \%$ after conventional transanal surgery [34]. If it is unclear that the TEM resection was radical, it is essential (and recommended) that an anterior resection be subsequently performed. This was the decision made in $12 \%$ of cases in our present series and in $21.4 \%$ of cases in the largest series reported by Buess's group [2]. In a series of 113 patients, Buess et al. found 5 residual tumors among a subset of 39 patients $(12.8 \%)$ who underwent an anterior resection immediately after TEM. The lymphadenectomy was negative in all cases for $\mathrm{T} 1$ tumor and positive in $23.3 \%$ of those with T2 and T3 tumors. In the entire series, the failure rate for $81 \mathrm{~T} 1$ tumors treated only by TEM was $4.5 \%(n=4)$, and for $22 \mathrm{~T} 1$ tumors requiring anterior resection following TEM it was $13.6 \%(n=3)$. The interpretation of these results is limited because the difference in the failure rates is not significant; moreover, the study was retrospective and may reflect a negative selection [2].

To date, the only published prospective, randomized study comprised 52 patients with $T 1$ tumors treated by TEM or anterior resection [11]. There were no significant differences in group outcome: The 5-year survival was $96 \%$; the local recurrence rate was $4.1 \%$ for TEM and $0 \%$ for anterior resection; and the metastasis rate was $0 \%$ for TEM and $4.1 \%$ for anterior resection. These results suggest that TEM may offer some advantage relative to anterior resection for $\mathrm{T} 1$ rectal cancer, with similar oncologic results [11]. Our results confirm this conclusion. However, our series is small and nonrandomized, making larger additional prospective and randomized studies essential to confrm the true value of TEM for treatment of early rectal cancer [26].

\section{TEM and Adjwant Therapy}

Conservative management of rectal cancer with radiotherapy or endocavitary contact radiotherapy has a $30 \%$ failure rate [35]. Consequently, the indications for neoadjuvant or adjuvant radiochemotherapy following local resection of rectal cancer by TEM remain controversial. In fact, local treatment of rectal cancer is limited by the impossibility of removing the potentially positive lymph node, supporting the concept of adjuvant radiotherapy, chemotherapy, or both to achieve local control of the lymph node [36]. The first published report on the combined effect of TEM resection for rectal cancer followed by radiotherapy appears to support such a benefit [18]. Recently published preliminary results suggest its reliability, with a 5 -year recurrence-free disease survival of $81 \%$ for irradiated patients versus $52 \%$ in those treated by local surgery alone [5]. However, except for T1 low grade tumors, there is currently a lack of evidence to recommend the use of TEM for curative treatment of rectal cancer, with or without adjuvant therapy.

\section{TEM and Palliative Therapy}

The use of TEM for purely palliative treatment of rectal cancer is not recommended [20]. In our limited experience (two cases), local resection of certain $\mathrm{T} 2$ tumors with TEM but without radiotherapy is viable for compromised patients or those who refuse a laparotony. However, only a few reports confirm this use of TEM, with a local complication rate of $14 \%[18,20,37]$. Palliative resection of a large infiltrative tumor is discouraged by Buess (personal communication), because of a high local complication rate and the difficulty achieving hemostasis. Although local surgical management is possible in such cases, radiochemotherapy should precede palliative surgical treatment and has been shown to facilitate surgical therapy in $83 \%$ of these patients [38]. Preliminary studies of the use of endoradiotherapy or perioperative radiotherapy in conjunction with local cancer resection of large turnors are under way $[38,39]$.

\section{Conclusions}

Transanal endoscopic microsurgical excision of rectal tumors is not only an additional tool for transanal resection of low rectal tumors but also a minimally invasive technique for treating tumors in the low, middle, and upper rectum. Compared with conven- 
tional transanal resection. TEM provides superior tumor exposure higher in the rectum (i.e., up to $18 \mathrm{~cm}$ ). The greater precision of resection. low morbidity ( $10 \%$, relative to anterior resection), and short duration of hospitalization (5 days) make this technique a reliable and in some cases more effective surgical approach than laparotomy and low anterior resection.

With strict patient selection and precise preoperative staging, the use of transanal endoscopic microsurgery for treatment of low risk $T 1$ carcinoma is possible with a lower complication rate than is seen with radical surgical therapy. Preliminary results suggest no difference in the 5-year survival rate for local and radical surgical therapy. For TEM, low risk cancer is defined as T1 tumors with differentiation G1-G2 without lymphangiosis carcinomatosa and a resection margin of at least $5 \mathrm{~mm}$ in patients older than 45 years. However, this recommendation must be tempered by the lack of controlled studies to provide support. According to the literature and to our own surgical experience to date, all other types of rectal cancer should be treated by total mesorectal excision [10]. The contribution of adjuvant therapy to local treatment of rectal cancer is still under evaluation [4].

\section{Résumé}

La microchirurgie transanale endoscopique (MTE) permet une excision locale des tumeurs situées entre 4 et $18 \mathrm{~cm}$ au-dessus de la ligne anocutanée. La technique n'est pas encore très répandue en raison du besoin d'une instrumentation et d'outils spécifiques, une technique un peu spéciale, et une sélection stricte des patients. Le but de cette étude prospective, descriptive, a été d'analyser les indications actuelles de cette technique et d'évaluer l'utilisation de ce procédé pour le traitement du cancer du rectum. En quatre ans, nous avons traité 50 patients âgés entre 31 et 86 ans (âge moyen $=64$ ans) par MTE pour tumeur rectale situeè à $12 \mathrm{~cm}$ (en moyenne) de la marge anale (extrêmes $4-18 \mathrm{~cm}$ ). Le taux de complications locales a été de $4 \%$. Soixante-six pourcent des lésions étaient bénignes et $24 \%$ des tumeurs T1 et T2. Parmi les 12 cas de cancer. quatre ont nécessité une réopération pour excision totale du mésorectum, les huit autres patients sont actuellement sous surveillance. Pendant la période de suivi de 30,6 mois (extrêmes $=11-54$ mois), le taux de récidive des tumeurs TI a été de 8,3\%. La MTE est une technique chirurgicale mini-invasive qui pourrait être appliquée à un sous-groupe de la population atteint de tumeur rectale. Comparée à la résection transanale conventionnelle, la MTE permet une meilleure exposition des tumeurs du haut rectum, c'est-à-dire jusqu'à $18 \mathrm{~cm}$ de la marge anale. Une grande précision dans la résection, combinée à une morbidité basse (par rapport à la résection antérieure) (10\%) et une courte hospitalisation (5,5 jours) rendent cette technique fiable, et dans certains cas, plus efficace que la résection antérieure par laparotomie.

\section{Resumen}

La microcirugia endoscópica transanal (TEM) permite la resección de tumores rectales localizados de 4 a $18 \mathrm{~cm}$ por encima del margen anal. Este procedimiento hasta ahora no se ha generalizado debido a la necesidad de desarrollar instrumentos y herramientas especiales, aspectos técnicos inusuales de abordaje y criterios estrictos para la selección de los pacientes. El objetivo de este estudio prospectivo y drescriptivo es analizar las indicaciones actualmente aceptadas para las TEM y evaluar la eficacia de esta técnica en el tratamiento del cáncer de recto. En un periodo de 4 años, 50 pacientes con edades comprendidas entre 31 y 86 años (media $=64$ años) fueron tratados mediante el procedimiento quirúrgico TEM, por padecer tumores rectales situados a $12 \mathrm{~cm}$ por encima del margen anal (rango: $4-18 \mathrm{~cm}$ ). La tasá de complicaciones locales fue del $4 \%$. En el $76 \%$ las lesiones fueron benignas y en el $24 \%$ malignas: tumores T1 y T2. De los 12 casos de cáncer, 4 requirieron una reintervención con resección total del mesorrecto; los otros 8 están actualmente controlados y sometidos a tratamiento. Tras un periodo de seguimiento de 30.6 meses (rango: $11-54$ meses) la tasa de recidivas de tumores $\mathrm{T} 1$ fue del $8.3 \%$. La TEM es una técnica quirúrgica minimamente invasiva que puede ser muy útil en un número reducido y escogido de pacientes con cáncer de recto. Comparada con la resección transanal convencional, la TEM permite la exposición de tumores del alto recto i.e. hasta $18 \mathrm{~cm}$ de los márgenes del ano. La gran precisión de la resección, junto con la baja morbilidad (en comparación con la resección anterior) $10 \%$ y la corta hospitalización (5.5 dias) hace que esta técnica sea, fiable y, en algunos casos, más eficaz que la laparotomía con resección anterior baja del recto.

\section{Acknowledgment}

We thank Winifred von Ehrenburg for helpful discussion and editorial advice.

\section{References}

1. Buess, G., Hutterer, F., Theiss, J., Böbel, M., Isselhard, W.. Pichlmaier, H.: Das System für die transanale endoskopische Rectumoperation. Chirurg 55:677, 1984

2. Mentges, B., Buess, G., Effinger, G., Manncke, K., Becker, H.D.: Indications and tesults of local treatment of tectal cancer. Br. J. Surg. $84: 348,1997$

3. Whitlow, C.B., Beck, D.E., Gathright, J.B.: Surgical excision of large rectal villous adenomas. Surg. Oncol. Clin. N. Am. 5:723, 1996

4. Weber, T.K., Petrelli, N.J.: Local excision for rectal cancer: an uncertain future. Oncology (Huntingt.) 12:933, 1998

5. Taylor, R.H., Hay, J.H., Larsson, S.N.: Transanal local excision of selected low rectal cancers. Am. J. Surg. 175:360, 1998

6. Massari, M., De Simone, M., Cioff, U., Rosso, L., Chiarelli, M., Gabrielli, F.: Value and limits of endorectal ultrasonography for preoperative staging of rectal carcinoma. Surg. Laparosc. Endosc. $8: 438,1998$

7. Kirwan, W.O., Turnbull, R.B., Jr., Fazio, V.W., Weakley, F.L.: Pullthrough operation with delayed anastomosis for rectal cancer. Br. J. Surg. 65:695, 1978

8. Buess, G.F.: Local surgical treatment of rectal cancer. Eur. J. Cancer $31 A: 1233,1995$

9. Von Flüc, M., Harder, F.: Transanal endoscopic microsurgery (TEM): indications and limitations. Schweiz. Med. Wochenschr. 124:1800, 1994

10. MacFarlane, J., Ryall, R., Heald, R.: Mesorectal excision for rectal cancer. Lancet 341:457, 1993

11. Winde, G., Notberg. H, Keller, R, Schmid, K.W., Bunte, H.: Surgical cure for early rectal carcinomas (T): transanal endoscopic microsurgery vs. antcrior resection. Dis. Colon Rectum 39:969, 1996

12. Said, S.. Stippel, D.: 10 Years experiences with transanal endoscopic microsurgery: bistopathologic and clinical analysis. Chirurg 67:139. 1996

13. Said, S., Stippel. D.: Transanal endoscopic microsurgery in large, sessile adenomas of the rectum: a 10-year experience. Surg. Endosc. $9: 1106,1995$

14. Steele, R.J., Hershman, M.J., Mortensen, N.J., Armitage, N.C.. 
Scholefield, J.H.: Transanal endoscopic microsurgery-initial experience from three centres in the United Kingdom. Br. I. Surg. 83:207. 1996

15. Smith, L.E., Ko, S.T.. Saclarides, T., Caushaj, P., Orkin, B.A., Khanduja, K.S.: Transanal endoscopic microsurgery: initial registry results. Dis. Colon Rectum 39:S79, 1996

16. Swanstrom, L.L., Smiley, P., Zelko, J., Cagle, L.: Video endoscopic transanal-rectal tumor excision. Am. J. Surg. 173:383, 1997

17. Morschel, M., Heintz, A., Bussmann, M., Junginger, T.: Follow-up after transanal endoscopic microsurgery or transanal excision of targe benign rectal polyps. Langenbecks Arch. Surg. 383:320, 1998

18. Lezoche, E., Guerrieri, M., Paganini, A.M., Feliciotti, F.: Transanal endoscopic microsurgical excision of irradiated and nonirradiated rectal cancer: a 5-year experience. Surg. Laparosc.Endosc. 8:249, 1998

19. Saclarides, T.J.: Transanal endoscopic microsurgery: a single surgeon's experience. Arch. Surg. 133:595, 1998

20. Turler, A., Schafer, H., Pichlmaier, H.: Role of transanal endoscopic microsurgery in the palliative treatment of rectal cancer. Scand. J. Gastroenterol. 32:58, 1997

21. Klaue, H.J. Bauer, E.: Retroperitoneal phlegmon after transanal endoscopic microsurgical excision of rectal adenoma. Chirurg 68:84, 1997

22. Hemingway, D., Flett, M., McKee, R.F., Finlay, I.G.: Sphincter function after transanal endoscopic microsurgical excision of rectal tumours. Br.J.Surg. 83:51, 1996

23. Kreis, M.E., Jehle, E.C., Haug, V., Manncke, K., Buess, G.F., Becker, H.D., Starlinger, M.J.: Functional results after transanal endoscopic microsurgery. Dis.Colon Rectum 39:1116, 1996

24. Banerjee, A.K., Jehle, E.C., Kreis, M.E., Schott, U.G., Claussen, C.D., Becker, H.D., Starlinger, M., Buess, G.F.: Prospective study of the proctographic and functional consequences of transanal endoscopic microsurgery. Br. J. Surg. 83:211, 1996

25. Winburn, G.B.: Surgical resection of villous adenomas of the rectum. Am. Surg. 64:1170, 1998

26. Winde, G.: Outcome following transanal endoscopic microsurgery. Dis. Colon Rectum 41:526, 1998

27. Heintz, A., Morschel, M., Junginger, T.: Comparison of results after transanal endoscopic microsurgery and radical resection for $\mathrm{T} 1 \mathrm{carci}-$ noma of the rectum. Surg. Endosc. 12:1145, 1998

28. Kato, K., Saito, T., Matsuda, M. Imai, M., Kasai, S., Mito, M.: Suc- cessful treatment of a rectal anastomotic stenosis by transanal endoscopic microsurgery (TEM) using the contact Nd:YAG laser. Surg. Endosc. 11:485, 1997

29. Salm, R, Lampe, H., Bustos, A., Matern, U.: Experience with TEM in Germany. Endosc. Surg. Allied Technol. 2:251, 1994

30. Nakagoe, T. Sawai, T., Uchikawa, T., Nanashima, A, Yamaguchi, H. Yasutake. T., Kusano, H., Ayabe, H.: Intragastric endoscopic surgery using the transanal endoscopic microsurgery technique. Br. J. Surg. $84: 830,1997$

31. Herzog, U., von Flue, M., Tondelli, P., Schuppisser, J.P.: How accurate is endorectal ultrasound in the preoperative staging of tectal cancer? Dis. Colon Rectum 36:127, 1993

32. Mainprize, K, Mortensen, N., Warren, B.: Early colorectal cancer: recognition, classification and treatment. Br. J. Surg. 85:469, 1998

33. Sizler, P.J., Seow-Cheon, F., Ho, Y.H., Leong, A.P.K.: Lymph node involvement and tumor depth in rectal cancers: an analysis of 805 patients. Dis. Colon Rectum 40:1472, 1997

34. Warneke, J., Petrelli, N.J., Herrera, L.: Local recurrence after sphincter-saving resection for rectal adenocarcinoma. Am. J. Surg. 158:3, 1989

35. Maingon, P., Guerif, S., Darsouni, R., Salas, S., Barillot, I., d'Hombres, A., Bone-Lepinoy, M.C., Fraisse, J., Horiot, J.C.: Conservative management of rectal adenocarcinoma by radiotherapy. Int. J. Radiat. Oncol. Biol. Phys. 40:1077, 1998

36. Bleday, R., Breen, E., Jessup, J.M., Burgess, A., Sentovich, S.M., Steele, G., Jr.: Prospective evaluation of local excision for small rectal cancers. Dis. Colon Rectum 40:388, 1997

37. Lezoche, E., Guerrieri, M., Paganini, A., Feliciotti, F., Di Pietrantonj, F.: Is transanal endoscopic microsurgery (TEM) a valid treatment for rectal tumors? Surg. Endosc. 10:736, 1996

38. Kim, H.K., Jessup, J.M., Beard, C.J., Bornstein, B., Cady, B., Stone M.D., Bleday, R., Bothe, A., Jr., Steele, G., Jr., Busse, P.M.: Locally advanced rectal carcinoma: pelvic control and morbidity following preoperative radiation therapy, resection, and intraoperative radiation therapy. Int. J. Radiat. Oncol. Biol. Phys. 38:777, 1997

39. Mendenhall, W.M., Rout, W.R., Vauthey, J.N., Haigh, L.S., Zlotecki, R.A., Copeland, E.M., III: Conservative treatment of rectal adenocarcinoma with endocavitary irradiation or wide local excision and postoperative irradiation. J. Clin, Oncol. 15:3241, 1997 